\title{
Lobbying and legislative organization the effect of the vote of confidence procedure
}

Bennedsen, Morten; Feldmann, Sven E.

Document Version

Final published version

Publication date:

2002

License

CC BY-NC-ND

Citation for published version (APA):

Bennedsen, M., \& Feldmann, S. E. (2002). Lobbying and legislative organization: the effect of the vote of confidence procedure.

Link to publication in CBS Research Portal

\section{General rights}

Copyright and moral rights for the publications made accessible in the public portal are retained by the authors and/or other copyright owners and it is a condition of accessing publications that users recognise and abide by the legal requirements associated with these rights.

Take down policy

If you believe that this document breaches copyright please contact us (research.lib@cbs.dk) providing details, and we will remove access to the work immediately and investigate your claim. 


\title{
Lobbying and Legislative Organization The Effect of the Vote of Confidence Procedure
}

\author{
Morten Bennedsen ${ }^{\dagger}$ And Sven E. Feldmann ${ }^{\ddagger}$
}

January 2002

\begin{abstract}
We analyze how the structure of organizational form of legislative institutions affects interest groups' incentives to lobby. Lobbying is modelled the strategic provision of information by an interest group to a multi-person legislature. We show that the effectiveness of lobbying lies in changing the viable policy coalitions. We show in a multi-period policy framework that a distinguishing feature between the US Congress and European parliamentary systems - the vote of confidence procedurecan significantly change the incentives for interest group lobbying.
\end{abstract}

We would like to thank Francesco Caselli, Urs Luterbacher, Christian Schulz, Ken Shepsle, Elu von Thadden, and Barry Weingast for helpful comments and David Baron for inspiring this project.

$\dagger$ CEBR (www.cebr.dk) and Department of Economics, Copenhagen Business School. Email:mb.eco@cbs.dk. WEB: www.cbs.dk/staff/mortenbennedsen/.

$\ddagger$ Harris School of Public Policy Studies, University of Chicago. Email:feld@uchicago.edu. 


\section{Introduction}

The extension of permanent normal trade relations (PNTR) to China in 2000 was hailed as a major political victory for the second Clinton administration. Despite heightened partisanship in Congress during that period, the coalition that supported and passed the bill in the House of Representative exhibited substantial partisan overlap: threequarters of the Republicans and one-third of the Democrats in the House voted for the bill, and it was clear that without the support from a substantial number of Democrats the bill would not have passed.

By all accounts, lobbying for and against the bill and for various provisions within it was very intense. ${ }^{1}$ Most likely, many legislators learned about the consequences of PNTR for their district and about certain details in the bill from an interest group that favored or opposed the China Trade bill for reasons quite independent of the ones shared with the legislator.

This example is far from unique. It is commonplace for policy entrepreneur to craft a legislative coalition in the U.S. Congress "opportunistically" so as to achieve their objective. By addressing a range of interests the sponsor can attract the support from members of the other party with very little sanctions from her own party nor for the supporters, unless the issue hits a partisan "nerve." In fact, many bills are jointly sponsored by members of both parties, underscoring the opportunistic nature of policy coalitions.

Likewise, interest groups that provide assessments of and recommendations for the design of legislation common, too. With hearings and open access, Congress is deftly prepared to collect information from a wide set of interests and permits interest groups

\footnotetext{
${ }^{1}$ Congressional Quarterly Weekly 58(16). 15 April 2000, p. 909.
} 
to weigh in on the policy debate. We need not assume that legislators are corruptible, gullible, or naive in order for information to make a difference in policy outcomes. Members, for their own benefit, pay heed to the information brought before them by interest groups and lobbyists. With time at a premium, information is welcome and can quickly be parsed for relevant and useful content.

The question is whether the openness to outside information and the flexibility with which policy coalitions are formed is a feature of Congress alone or whether it is common among the legislatures around the world. While this is an empirical question, we propose here a formal model that provides a theoretical answer. Casual empirical evidence, however, points in the same direction as our theoretical results: Congress is quite unique in these features.

Others have pointed out that party strength and the cohesion among members of a government coalition in parliamentary systems tend to exceed that of the two parties in the U.S. Congress (Mezey 1979; Loewenberg and Patterson 1988). At the same time, the legislative process in parliamentary democracies is by far not as open to a broad range of interest groups. Legislative committee hearings are much rarer and less expansive, and fewer interest groups bother to contact legislators (Liebert 1995, von Beyme 1998). Legislators seem to rely for their information to a greater extent on governmental sources outside the legislature, including the administration and state governments, and on a narrow set of well-entrenched constituencies.

In this paper we focus on the incentives the legislative organization provides for interest groups to lobby in the legislative process. Lobbying as information provision has been studied in the literature (Calvert 1985; Austen-Smith 1998; de Figueiredo, Spiller, and Urbiztondo 1999; Bennedsen and Feldmann 2001). In the present analysis 
we show that the willingness of interest groups to strategically provide information in order to obtain more favorable outcomes depends, inter alia, on the structure of the decision making institutions. The lobbying effort is contingent on the legislative organization. It turns out that, in accordance with Mayhew (1974), the organization of Congress is particularly apt to serve the -informational - needs of its members.

Huber (1996) shows that the vote of confidence procedure is a salient institutional feature of a parliamentary system. Diermeier and Feddersen (1998) formalize the role of the vote of confidence procedure in creating cohesion within the governing coalition in a dynamic, multi-period model. We adopt their model here in a simplified fashion to study informational lobbying in a comparative context. In Bennedsen and Feldmann (2002) we show that if government membership creates a positive rent, then the confidence procedure tends to reduce informational lobbying. In the present paper we extend that analysis into a dynamic model of legislative bargaining and compare the incentive to lobby a Congressional system (CS) without confidence procedure and a parliamentary system (PS) that provides the confidence procedure.

\section{The Model}

\section{The Legislature}

Consider a legislature composed of three legislators, $i$, each representing a district. The legislature meets for a term of $T$ policy periods, after which it faces mandatory reelection. ${ }^{2}$ The session begins with an organizational period in which the government coalition is formed. The subsequent periods are policy periods, during which a member

\footnotetext{
${ }^{2}$ For convenience we number periods in reverse order, i.e., the last policy period is period 1 and the first period is period $T$.
} 
of the government coalition is (randomly) selected to make a policy proposal. ${ }^{3}$ The proposal is voted on by majority rule, and the next period begins.

The difference between the Congressional and the parliamentary systems lies in the consequence of a failed vote. In the congressional system, when a policy proposal fails, then no policy is adopted and the legislature moves to the next policy period. The parliamentary system, on the other hand, allows the confidence procedure to be invoked: when the procedure has been invoked and the proposed policy proposal fails, then the government steps down and a new government is formed. The fate of the government coalition is thus tied to the outcome of the vote on the proposal.

Since we are not interested in the government formation process per se, we simply assume that the government is formed by a random draw of two (of the three) members by Nature.

\section{The Policy Process and Lobbying}

Within each policy period $\tau$, the legislature decides on the allocation of a distributive policy, i.e., on the distribution of local public goods to the three districts. ${ }^{4}$ Let $G^{\tau}$ be the total amount of public goods to be distributed in period $\tau$, and $\mathbf{g}^{\tau}=\left(g_{1}^{\tau}, g_{2}^{\tau}, g_{3}^{\tau}\right)$ the vector of the allocation such that $G^{\tau}=\sum_{i=1}^{3} g_{i}^{\tau}$. The dead-weight loss of government spending is assumed to be increasing, so that the cost of providing $\mathbf{g}^{\tau}$ is convex in the total distribution; we assume a simple cost function $C\left(\mathbf{g}^{\tau}\right)=\frac{1}{2}\left(G^{\tau}\right)^{2}$. We assume that there is a balanced budget within each period and that costs are shared equally among the districts through lump sum taxation, such that each district's tax burden in period

\footnotetext{
${ }^{3}$ The structure of this policy game is similar to Diermeier and Feddersen (1998). In the Congressional system the "government coalition" is simply the Congressional majority.

${ }^{4}$ See Baron (1994) for a discussion of distributive policies.
} 
$\tau$ is $\frac{1}{6}\left(G^{\tau}\right)^{2}$. The net benefit to district $i$ from allocation $\mathbf{g}^{\tau}$ in period $\tau$ is given by

$$
u_{i}\left(\mathbf{g}^{\tau}\right)=\theta_{i} g_{i}^{\tau}-\frac{1}{6}\left(G^{\tau}\right)^{2}
$$

where $\theta_{i}$ is the district's (marginal) valuation of the public good.

Districts can be of two types, $\theta_{i} \in\{\underline{\theta}, \bar{\theta}\}$, with $0<\underline{\theta}<\bar{\theta}$. The distribution of type is such that $\theta_{i}=\bar{\theta}$ with probability $p$ and $\theta_{i}=\underline{\theta}$ with probability $(1-p)$, ex ante. We assume that the $\theta_{i}$ 's are uncorrelated across districts and across policy rounds (i.e., each period deals with a different distributional policy). In any decision a legislator $i$ faces, she seeks to maximize the expected sum of benefits accruing to her district during the remainder of the legislative session, $\sum_{j=1}^{\tau} \mathrm{E}\left[u_{i}\left(\mathbf{g}^{j}\right)\right]$.

Lobbying is the strategic transmission of decision-relevant information to members of the legislature. The uncertainty legislators face in this model is the value each district derives from the local public good. By providing information about districts' valuation of the public good, a lobby group can potentially affect the allocation of the public good to the districts.

Suppose in each period $\tau$ a lobby group, e.g., the producer or the national representative for the beneficiaries of the public good, is interested in increasing the aggregate amount of the policy that is being allocated. The group can search, i.e., it can obtain a signal about a district's valuation, and then decide whether it wants to reveal this information to the decision makers. We assume that the search activity is costless for the lobby group and observable by the legislature. ${ }^{5}$

When the interest group searches for information about district $i$ 's valuation, it

\footnotetext{
${ }^{5}$ The assumption that search is costless can easily be relaxed. We deal extensively with unobservable search in Bennedsen and Feldmann (2001) and show there that the basic logic of what follows carries through.
} 
receives a signal $\sigma_{i}$, which with probability $q$ reveals the district's true type, $\sigma_{i}=\theta_{i}$, and with probability $1-q$ is uninformative, $\sigma_{i}=\emptyset$. After the proposer is chosen from the government coalition, the interest group lobbies the legislature by sending a vector of messages $\boldsymbol{\mu}=\left(\mu_{1}, \mu_{2}, \mu_{3}\right),{ }^{6}$ where $\mu_{i} \in\left\{\sigma_{i}, \emptyset\right\}$. In other words, this model of informational lobbying assumes that information is "hard" evidence, i.e., the group can transmit or withhold evidence, but it cannot "lie" by forging information. Once the message is sent, the proposer chooses a policy allocation $\mathbf{g}^{\tau}$, and the legislature votes on the proposal via majority rule.

In summary, the sequence of moves within each policy period is:

1. The lobby group decides upon its search activity.

2. Nature chooses a proposer randomly from the government coalition.

3. The lobby group delivers its message to the legislature.

4. Proposer chooses a policy allocation. In the PS, the proposer also decides upon the use of the confidence procedure.

5. The legislature votes on the proposal. If the proposal is rejected, the allocation to each district is zero. In the PS, if the confidence procedure has been invoked, losing the vote also forces the government to step down and a new government coalition is drawn by Nature for the next policy period.

In step 2 above, Nature designates one of the two legislators in the government coalition as the proposer (or agenda setter), and the other as coalition partner. The third legislator, who is not a member of the governing coalition, remains the minority

\footnotetext{
${ }^{6}$ The message vector is sent to all legislators simultaneously. This is without loss of generality since the lobby group's optimal strategy is to reveal high values of $\theta$ only even if messages were privately sent to individual legislators.
} 
legislator. We will thus refer to the three legislators (and the three districts) using the subscripts $a s, c p$, and $m i$. In any given policy period the proposer may choose to include the coalition partner and/or the minority legislator in a policy coalition.

Finally, in step 5, we make the assumption, which is standard in setter games, that when a legislator is indifferent between voting for the proposal or against it she resolves the indifference by voting for the proposal.

\section{Results}

We solve for the optimal strategies in this game by backward induction. Our equilibrium concept is Perfect Bayesian Nash equilibrium. One characteristic feature of the Congressional legislative system is that it does not have a vote of confidence procedure, i.e., even if the government, or majority party, looses important votes, it does not step down. In fact, this happens quite frequently. We focus on showing what the optimal lobbying strategy is for the lobby group and we use this as a benchmark against which we in the next section measure the lobby's incentive to engage in information provision

in the presence of a vote of confidence procedure. However, before we can analyze the lobby's value from searching for information, we need to know what the aggregate level of public good for given expectations of districts' marginal benefit will be, i.e. we need to know what $G$ the agenda setter optimally proposes.

\section{Informational Lobbying in the Last Period}

Let us start by considering the last policy period of the legislative term. After this period the government must step down, which renders the confidence procedure innocuous since all it can do is force the government to step down if the proposal is 
rejected. The Congressional and the parliamentary systems are thus equivalent in this case.

The agenda setter optimally proposes an allocation of the public goods that maximizes the net benefits to his district subject to the condition that the proposed allocation will be supported by a majority of the legislators, i.e., by at least one other legislator. Since for any total allocation $G$ a second legislator's participation constraint is easier to satisfy the higher her valuation of the public good is, the agenda setter will include the legislator as partner in the policy coalition whose expected valuation $\mathrm{E} \theta_{j}$ is higher, and allocate sufficient public goods to the partner's district so that her participation constraint is met. The remaining legislator receives an allocation of zero. (If the other two legislators have the same expected marginal utility, the agenda setter picks randomly one of them as her policy coalition partner.)

Solving this constrained maximization problem is straightforward and yields the following aggregate level of public good:

$$
\begin{aligned}
G^{*} & =3 \frac{\mathrm{E} \theta_{a s} \cdot \mathrm{E} \theta_{j}}{\mathrm{E} \theta_{a s}+\mathrm{E} \theta_{j}}, \\
\text { with } j & =\underset{i \in\{c p, m i\}}{\arg \max } \mathrm{E} \theta_{i} .
\end{aligned}
$$

The aggregate allocation of public good is thus an increasing and strictly concave function of the the expected marginal benefits for each of the two policy coalition partners. Since we are interested in the lobby group's behavior, and the lobby by assumption only cares about the aggregate amount of public good, we do not need to state the actual allocation of public good to each region. We define $G^{*}(\cdot, \cdot)$ as a function with two arguments given in (2).

We can now analyze the group's search and information transmission behavior 
in period 1. We will show that, given the agenda's best response function $G^{*}$, the interest group has a unique best lobbying strategy. By searching in a district, the group may be able to reveal that the district's valuation is high, or it may not be able to convey positive information, in which case the agenda setter updates his belief about the district's valuation. As a matter of notation, let $\mathrm{E}\left(\theta_{i} \mid\right.$ no search in $\left.i\right)=\theta^{\circ}$ be the ex ante expectation of the district's type given the prior distribution $\theta_{i}$, and let $\mathrm{E}\left(\theta_{i} \mid\right.$ unsuccessful search in $\left.i\right)=\theta^{s}$ be the posterior expectation of $\theta_{i}$ after the interest group searched for information in district $i$ and did not reveal any positive finding. ${ }^{7}$

The interest group needs to choose in which districts to search so as to raise the expected valuations in the policy coalition. In the last policy period the lobby strictly prefers to search for information. This is easily seen by considering a search in the minority district only: With probability $p q$ the lobby finds evidence for $\theta_{m i}=\bar{\theta}$, which implies that the proposer would choose the minority district as a majority partner. If the lobby does not find this positive evidence, the proposer lowers his expectation about the minority district's valuation of the public good and will choose the $c p$ as partner in the policy coalition, and the aggregate good will be as high as if the interest group had not searched. The interest group's expected value of searching in the minority district relative to not searching is

$$
V_{m i}=p q\left[G^{*}\left(\theta^{\circ}, \bar{\theta}\right)-G^{*}\left(\theta^{\circ}, \theta^{\circ}\right)\right]>0 .
$$

The following lemma verifies that this is indeed the group's optimal search strategy by calculating the corresponding values for all search strategies.

\footnotetext{
${ }^{7}$ Naturally, $\theta_{i}^{\circ}=(1-p) \underline{\theta}+p \bar{\theta}$. An unsuccessful search from the interest group's point of view comprises the events $\sigma_{i}=\underline{\theta}$ or $\sigma_{i}=\emptyset$. The interest group always transmits a favorable signal and withholds an unfavorable one so that, using Bayes' Rule, we have $\theta_{i}^{s}=\frac{1-p}{1-p q} \underline{\theta}+\frac{p-p q}{1-p q} \bar{\theta}$. Note that $\theta_{i}^{s}<\theta_{i}^{\circ}$.
} 
Lemma 1. In the last policy period the interest group's unique optimal search strategy, in both legislative systems, is to search in the minority district alone.

Proof. We have already argued that in the last policy period the confidence procedure has no effect on the behavior of the legislators. Thus, the interest group's optimal search strategy will be the same in both legislative systems. It remains to show what this strategy is.

Since the group does not know at the time of searching which member of government will be selected as the agenda setter, there are five distinct search strategies. Analogous to $V_{m i}$ above we calculate the net gain for each of these remaining search strategies: $V_{g v}$ (search in one government member's district), $V_{g v, g v}$ (search in both government members' districts), $V_{g v, m i}$ (search in one government member's district and the minority legislator's district), and $V_{g v, g v, m i}$ (search in all three districts). 


$$
\begin{aligned}
& V_{g v}=\frac{1}{2}\left[p q G^{*}\left(\bar{\theta}, \theta^{\circ}\right)+(1-p q) G^{*}\left(\theta^{s}, \theta^{\circ}\right)\right] \\
& +\frac{1}{2}\left[p q G^{*}\left(\bar{\theta}, \theta^{\circ}\right)+(1-p q) G^{*}\left(\theta^{\circ}, \theta^{\circ}\right)\right]-G^{*}\left(\theta^{\circ}, \theta^{\circ}\right)<V_{m i}, \\
& V_{g v, m i}=\frac{1}{2}\left\{(p q)^{2} G^{*}(\bar{\theta}, \bar{\theta})+p q(1-p q)\left[G^{*}\left(\theta^{s}, \bar{\theta}\right)+G^{*}\left(\bar{\theta}, \theta^{\circ}\right)\right]+(1-p q)^{2} G^{*}\left(\theta^{s}, \theta^{\circ}\right)\right\} \\
& +\frac{1}{2}\left[\left(2 p q-p q^{2}\right) G^{*}\left(\bar{\theta}, \theta^{\circ}\right)+(1-p q)^{2} G^{*}\left(\theta^{\circ}, \theta^{s}\right)\right]-G^{*}\left(\theta^{\circ}, \theta^{\circ}\right) \\
& <\frac{1}{2}\left[p q G^{*}\left(\theta^{\circ}, \bar{\theta}\right)+(1-p q) G^{*}\left(\theta^{\circ}, \theta^{\circ}\right)\right] \\
& +\frac{1}{2}\left[p q G^{*}\left(\bar{\theta}, \theta^{\circ}\right)+(1-p q) G^{*}\left(\theta^{\circ}, \theta^{\circ}\right)\right]-G^{*}\left(\theta^{\circ}, \theta^{\circ}\right)=V_{m i}, \\
& V_{g v, g v}=(p q)^{2} G^{*}(\bar{\theta}, \bar{\theta})+p q(1-p q)\left[G^{*}\left(\bar{\theta}, \theta^{\circ}\right)+G^{*}\left(\bar{\theta}, \theta^{s}\right)\right] \\
& +(1-p q)^{2} G^{*}\left(\theta^{s}, \theta^{\circ}\right)-G^{*}\left(\theta^{\circ}, \theta^{\circ}\right) \\
& <p q G^{*}\left(\bar{\theta}, \theta^{\circ}\right)+(1-p q) G^{*}\left(\theta^{\circ}, \theta^{\circ}\right)-G^{*}\left(\theta^{\circ}, \theta^{\circ}\right)=V_{m i} . \\
& V_{g v, g v, m i}=p q\left[\left(2 p q-p q^{2}\right) G^{*}(\bar{\theta}, \bar{\theta})+(1-p q)^{2} G^{*}\left(\bar{\theta}, \theta^{s}\right)\right] \\
& +(1-p q)\left[\left(2 p q-p q^{2}\right) G^{*}\left(\theta^{s}, \bar{\theta}\right)+(1-p q)^{2} G^{*}\left(\theta^{s}, \theta^{s}\right)\right]-G^{*}\left(\theta^{\circ}, \theta^{\circ}\right) \\
& <p q\left[p q G^{*}(\bar{\theta}, \bar{\theta})+(1-p q) G^{*}\left(\bar{\theta}, \theta^{\circ}\right)\right]+ \\
& (1-p q)\left[p q G^{*}\left(\theta^{s}, \bar{\theta}\right)+(1-p q) G^{*}\left(\theta^{s}, \theta^{\circ}\right)\right]-G^{*}\left(\theta^{\circ}, \theta^{\circ}\right) \\
& <p q G^{*}\left(\theta^{\circ}, \bar{\theta}\right)+(1-p q) G^{*}\left(\theta^{\circ}, \theta^{\circ}\right)-G^{*}\left(\theta^{\circ}, \theta^{\circ}\right)=V_{m i} .
\end{aligned}
$$

Each inequality above follows from Jensen's inequality and the fact that the agenda setter's response function $G^{*}(\cdot)$ is strictly concave. Thus, $V_{m i}$ maximizes the expected allocation of public good.

We have now shown that in the last policy period of the legislative term, Congressional system and parliamentary system provide the exact same incentive to lobby. In particular, the interest group collects information about a "marginal" district, one that 
would not otherwise be included in the policy coalition, and manages to change both the composition of the policy coalition as well as the allocation of policy so that the overall outcome is in its favor.

\section{Lobbying in Absence of the Confidence Vote Procedure}

In this section we work our way backwards for the game without the vote of confidence procedure. A legislator in period $\tau$ maximizes her expected future benefits over the remainder of the legislative term, i.e.,

$$
U_{i}=\sum_{j=1}^{\tau} \mathrm{E}\left[u_{i}\left(\mathbf{g}^{j}\right)\right]
$$

We denote by $v_{i}^{\tau}=\sum_{j=1}^{\tau-1} \mathrm{E}\left[u_{i}\left(\mathbf{g}^{j}\right)\right]$ the continuation value of the game in period $\tau$. Hence the legislator is maximizing

$$
U_{i}=r_{i} g_{i}^{\tau}-\frac{1}{6}\left(G^{\tau}\right)^{2}+v_{i}^{\tau}
$$

We will show below that $v_{i}^{\tau}$ is identical for the two members of the governing coalition, and we will refer to it as $v_{\text {gov }}^{\tau}$; the continuation value for the minority legislator is strictly lower. The "value" of being in the government coalition in period $\tau$ is therefore $\delta_{\text {gov }}^{\tau} \equiv v_{\text {gov }}^{\tau}-v_{m i}^{\tau}$. This value will play a central role in a legislature with a vote of confidence procedure.

In the absence of the confidence procedure there is no strategic link between the policy periods. To see this, consider the voting decision by a non-proposing legislator $i$ facing a proposal $\mathbf{g}^{\tau}$ at date $\tau$. She supports the proposal if and only if her utility from the proposal plus the continuation value $v_{i}^{\tau}$ of future policy periods is greater than her utility from an allocation $g_{i}^{\tau \prime}=0$ with no tax cost, plus $v_{i}^{\tau}$. Thus, $v_{i}^{\tau}$ does not affect the legislator's voting decision. Furthermore, since the utility function is additively 
separable, $v_{a s}^{\tau}$ does not affect the agenda setter's own utility from a given proposal (see (3)). Finally, $\mathbf{g}^{\tau}$ does not affect the expected value of future policy periods since, by assumption, the budget is balanced within each period. ${ }^{8}$ The interest group in period $\tau$ also faces no strategic consideration as it only operates in this period.

The absence of a strategic link between the policy periods implies that each period in the legislative game without confidence procedure is strategically equivalent to the last period. We can therefore state the following Lemma without proof:

Lemma 2. In the dynamic policy game without vote of confidence procedure (congressional system), in each policy period $\tau$ the interest group's unique optimal search strategy is to search in the minority district alone.

The solution to our legislative game without vote of confidence procedure can be summarized as follows. First, Nature draws the government coalition. Then in each policy period the active lobby group searches for information in the minority district. If the lobby finds positive information about a high marginal valuation of the public good in the minority district, it transmits this information to the legislature. If the lobby delivers evidence for high valuation, the proposer reaches beyond the governing coalition (majority) and picks the outside district as a policy partner to support the current policy, with no repercussion for the future of the governing coalition. In case of no evidence from the lobby or evidence of low valuation, the proposer picks her government partner as the policy partner. ${ }^{9}$ The agenda setter proposes an aggregate

\footnotetext{
${ }^{8}$ In addition, inter-period reciprocal arrangements between legislators cannot be sustained since they would break down in the last period and thus unravel by backward induction.

${ }^{9}$ In the established equilibrium the lobby may also deliver information about low marginal valuation, since the minority district is excluded from the policy majority as long as there is no positive evidence for high valuation.
} 
amount of public good given in (2) and distributes it such that the non-policy partner receives zero public good, the policy partner receives sufficient amount of public good to weakly support the proposal, and the agenda setter receives the rest.

\section{Lobbying and the Role of the Confidence Vote}

The ability to link a policy proposal to a confidence vote creates a truly dynamic model with strategic interdependence across policy periods. To see this, consider the government coalition partner's $(p c)$ evaluation of a given policy proposal to which a confidence vote is attached. If he supports the proposal he will still be in the government coalition in the next period, which has a positive value to him. If he rejects the policy proposal and the proposal fails, the government steps down, and with a probability of $2 / 3$ he will participate in the next government (this is identical for all $i$ ). In other words, he expects to lose $\frac{1}{3} \delta_{\text {gov }}^{\tau}$ by causing the proposal to fail. Hence, $c p$ 's voting decision in period $\tau$ is affected by the size of $\delta_{g o v}^{\tau}$, which depends on the payoffs of future periods (except when $\tau=1$, the last period before mandatory election).

We now find equilibrium behavior in the dynamic model with confidence vote by solving the game backwards from period 1. In particular, we need to determine how the $v_{i}^{\tau}$ develop over time.

In Proposition 1 below we state, that when the proposer can link its policy proposal to a vote of confidence and there are sufficiently many policy periods remaining, then a lobby has less incentive to search than without the confidence procedure. In particular, we show that the lobby does not gain from using the search strategy that is optimal in the congressional system. Hence, the expected gain from searching, and thus the lobby's

incentive to search, is strictly smaller (possible negative) than in the congressional system. 
Date 1: The continuation value in period $1, v_{i}^{1}$, is normalized to zero for all legislators as the government needs to step down for sure at the end of the period. By Lemma 1, the lobby group's unique optimal search strategy is to search in the minority district and to report any positive finding. The proposer chooses as policy partner the one with the highest expected $\theta_{i}$. The expected utility in period 1 for the agenda setter, $u_{a s}^{1}$, the coalition partner, $u_{c p}^{1}$, and the minority legislator, $u_{m i}^{1}$, are

$$
\begin{aligned}
& u_{a s}^{1}=p q \psi_{a s}\left(\theta^{\circ}, \bar{\theta}\right)+(1-p q) \psi_{a s}\left(\theta^{\circ}, \theta^{\circ}\right) \\
& u_{c p}^{1}=-\frac{p q}{3} G^{*}\left(\theta^{\circ}, \bar{\theta}\right)^{2} \\
& u_{m i}^{1}=-\frac{1-p q}{3} G^{*}\left(\theta^{\circ}, \theta^{\circ}\right)^{2}
\end{aligned}
$$

$\psi_{a s}\left(\theta_{a s}, \theta_{j}\right)=u_{a s}\left(\mathbf{g}^{*}\right)$ is the agenda setter's utility from the optimal policy allocation, which depends, like $G^{*}$, on the districts' valuations of the public good. It is easy to show that $\psi_{a s}\left(\theta_{a s}, \theta_{j}\right)=\frac{3}{2} \frac{\theta_{a s}^{2} \theta_{j}}{\theta_{a s}+\theta_{j}}$.

Inspecting (4) we observe that the coalition partner's expected benefits is her expected tax share whenever the lobby group does find evidence for high valuation in the minority district, since she receive a zero expected benefit whenever she is included in the policy coalition. The expected benefit for the minority district is, similarly, the expected tax share times the probability of not being included in the policy coalition. In the last policy period (period 1) the proposer has no incentive to attach the confidence vote.

Date $\tau>1$ : The continuation value $v_{\text {gov }}^{\tau}$ for the members of the governing coalition arises from the likelihood of being the proposer in the next period. If the government remains in power at date $\tau$, each of the two legislators in the governing coalition has probability $1 / 2$ of being the proposer at date $\tau-1$. This probability drops to $1 / 3$ 
if the government is dissolved and newly formed.

In period $\tau$ the lobby group has the highest incentive to engage in information provision when the search strategy identified in Lemma 1 (i.e., searching in district $m i$ ) such that the proposer is willing to change the majority composition in response to the message received from the lobby group. Assume this is the case for all subsequent periods 1 through $(\tau-1)$. The following Lemma describes the laws of motion for the continuation value $v_{\text {gov }}^{\tau}$ and the expected utilities, for any period $\tau$.

Lemma 3. Suppose in each period $1, \ldots, \tau$ the lobby searches in the minority district only and that the proposer includes the minority district in the policy coalition if and only if the lobby provides positive evidence for $\theta_{m i}=\bar{\theta}$. Then for $\tau>1$,

$$
\begin{aligned}
v_{g o v}^{\tau} & =h(\tau)\left(u_{a s}^{1}+u_{c p}^{1}\right)-k(\tau) u_{m i}^{1} \\
u_{a s}^{\tau} & =[1+(2-p q) h(\tau)] u_{a s}^{1}+(2-p q) h(\tau) u_{c p}^{1}-(2-p q) k(\tau) u_{m i}^{1} \\
u_{c p}^{\tau} & =p q h(\tau) u_{a s}^{1}+[1+p q h(\tau)] u_{c p}^{1}-p q k(\tau) u_{m i}^{1} \\
u_{m i}^{\tau} & =\tau u_{m i}^{1}
\end{aligned}
$$

where

$$
h(\tau) \equiv \frac{1}{2} \sum_{i=1}^{\tau-1}\left(\frac{1}{3}\right)^{i} \quad \text { and } \quad k(\tau) \equiv \sum_{i=1}^{\tau-1}\left(\frac{1}{3}\right)^{i}(\tau-i) .
$$

Proof. The proof is by induction.

Date 2. The continuation value for each member of the governing coalition is

$$
v_{\text {gov }}^{2}=\frac{1}{6}\left(u_{a s}^{1}+u_{c p}^{1}\right)-\frac{1}{3} u_{m i}^{1}=h(2)\left(u_{a s}^{1}+u_{c p}^{1}\right)-k(2) u_{m i}^{1} .
$$

By assumption the lobby searches only in the minority district and the proposer is willing to include this district in a policy majority if $\mu_{m i}=\bar{\theta}$. Thus, with probability $p q$ the proposer picks $m i$ as a policy coalition partner without invoking the confidence 
procedure. With probability $1-p q$ the proposer uses $c p$ to support the policy and extracts the rent (continuation value) by attaching a confidence vote. Whichever legislator is picked as policy partner receives reservation utility zero. Thus, the expected utilities for the proposer, the coalition partner and the minority legislator are,

$$
\begin{aligned}
u_{a s}^{2} & =u_{a s}^{1}+(2-p q) v_{\text {gov }}^{2} \\
& =[1+(2-p q) h(2)] u_{a s}^{1}+(2-p q) h(2) u_{c p}^{1}-(2-p q) k(2) u_{m i}^{1}, \\
u_{c p}^{2} & =u_{c p}^{1}+p q v_{g o v}^{2}=p q h(2) u_{a s}^{1}+[1+p q h(2)] u_{c p}^{1}-p q k(2) u_{m i}^{1}, \\
u_{m i}^{2} & =2 u_{m i}^{1} .
\end{aligned}
$$

Date $\tau>2$. Assume the Lemma true for all number of periods up to $\tau-1$. The continuation value for each coalition partner in period $\tau$ is,

$$
\begin{aligned}
v_{\text {gov }}^{\tau} & =\frac{1}{6}\left(u_{a s}^{\tau-1}+u_{c p}^{\tau-1}\right)-\frac{1}{3} u_{m i}^{\tau-1} \\
& =\frac{1}{6}(1+2 h(\tau-1))\left(u_{a s}^{1}+u_{c p}^{1}\right)-\left(\frac{1}{3} k(\tau-1)+\frac{1}{3}(\tau-1)\right) u_{m i}^{1} \\
& =\frac{1}{6}\left(1+2 \sum_{i=1}^{\tau-2}\left(\frac{1}{3}\right)^{i}\right)\left(u_{a s}^{1}+u_{c p}^{1}\right)-\left(\frac{1}{3} \sum_{i=1}^{\tau-2}\left(\frac{1}{3}\right)^{i}(\tau-1-i)+\frac{1}{3}(\tau-1)\right) u_{m i}^{1} \\
& =h(\tau)\left(u_{a s}^{1}+u_{c p}^{1}\right)-k(\tau) u_{m i}^{1}
\end{aligned}
$$

Given $v_{\text {gov }}^{\tau}$ the expected payoffs for the legislators are,

$$
\begin{aligned}
u_{a s}^{\tau} & =u_{a s}^{1}+(2-p q) v_{g o v}^{\tau} \\
& =(1+(2-p q) h(\tau)) u_{a s}^{1}+(2-p q) h(\tau) u_{c p}^{1}-(2-p q) k(\tau) u_{m i}^{1}, \\
u_{c p}^{\tau} & =u_{c p}^{1}+p q v_{g o v}^{\tau}=p q h(\tau) u_{a s}^{1}+(1+p q h(\tau)) u_{c p}^{1}-p q k(\tau) u_{m i}^{1}, \\
u_{m i}^{\tau} & =\tau u_{m i}^{1} .
\end{aligned}
$$


Suppose now that the lobby in period $\tau$ provides positive evidence for a high valuation in the minority district, $\mu_{m i}=\bar{\theta}$. The proposer is willing to forego the benefit of the confidence procedure if and only if,

$$
\psi_{a s}\left(\theta^{\circ}, \bar{\theta}\right) \geq \psi_{a s}\left(\theta^{\circ}, \theta^{\circ}\right)+v_{\text {gov }}^{\tau} .
$$

Since $u_{m i}<0, h(\tau)$ is increasing and bounded, and $k(\tau)$ grows without bound, we observe that $v_{\text {gov }}^{\tau}$ increases without bound as $\tau$ increases; therefore the proposer will always prefer using the confidence procedure and require the support from the coalition partner whenever $\tau$ is large enough. Let $\bar{t}$ be the maximum $\tau$ for which (6) holds, and define $t^{*}=\min \{\bar{t}, T\}$. Thus, for $\tau \leq t^{*}$ the proposer is willing to craft the coalition opportunistically when she receives information from the lobby group.

When $\tau>t^{*}$, the proposer enforces voting cohesion among the government coalition. Hence, the lobby may either choose another search strategy that is able to affect the composition of the majority or abstain from searching. In the former case, Lemma 1 proves these strategies have a lower expected gain for the lobby group. We thus arrive at the following proposition:

Proposition 1. For all policy periods $\tau$ from $T$ to $t^{*}+1$ an interest group's expected gain from searching and providing information is strictly smaller in the system with confidence procedure than in the system without the confidence procedure. In the last $t^{*}$ policy periods the two systems provide an interest group with the same expected gain from lobbying.

The proposition states that for periods $\tau>t^{*}$ incentive for an interest group to engage in informational lobbying is strictly smaller in the parliamentary system than it is in the Congressional system. The intuition behind this result can be provided 
in two steps: First, having a large number of policy periods remaining before the end of the legislative term increases the value of belonging to the governing coalition. As Diermeier and Feddersen have shown, this implies that the members of the governing coalition have an incentive to support the proposals put forward by other members of the governing coalition, so that the vote of confidence procedure enhances voting cohesion among coalition partners. Second, a national lobby group's incentives to provide information is based on its ability to influence the composition of the policy coalition, and thereby to affect policy choices. If the value of government membership is high enough, and if the proposer is willing to invoke the confidence procedure and enforce voting cohesion, then there is little role for the interest group to affect the composition of the policy majority. Hence, the interest group's incentive for informational lobbying is diminished.

A second implication of Proposition 1 is that the activity of informational lobbying in the parliamentary system should be increasing over the course of the legislative term. The closer to the mandatory election date, the more impact will the transmitted information have as it is increasingly likely to affect the composition of the policy coalition; at the same time, voting cohesion in the legislature should decline. In a Congressional legislature our model predicts a constant, high level of informational lobbying.

\section{Examples}

The relevance of the identified difference in relative incentives to engage in informational lobbying in the Congressional and a parliamentary systems depends on the size of $t^{*}$. In this section we explore the range of parameters for which Proposition 1 is 


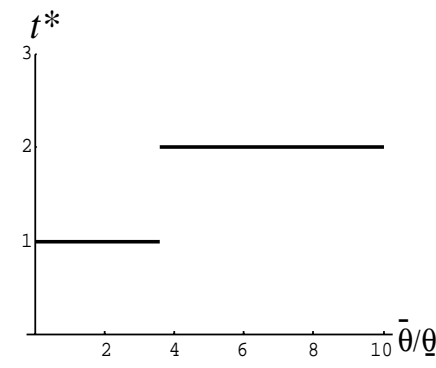

(a)

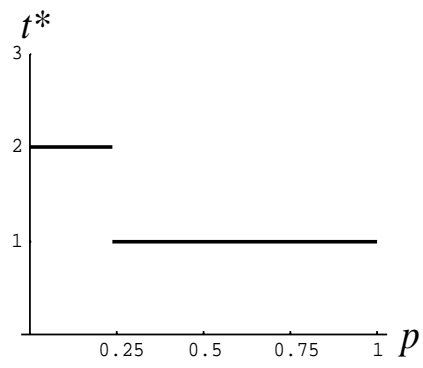

(b)

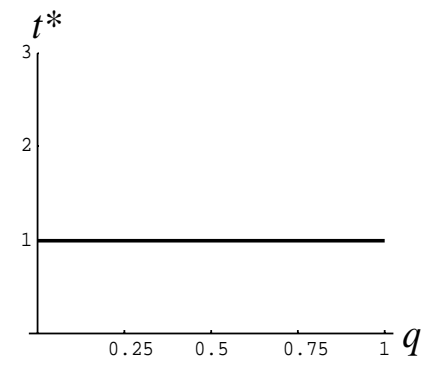

(c)

Figure 1: The number of periods for which the two legislative structures provide the same incentives for lobby groups to engage in information gathering. Panel (a): $p=0.5$ and $q=0.5$; Panel (b): $\bar{\theta} / \underline{\theta}=2$ and $q=0.5$; and, Panel (c): $\bar{\theta} / \underline{\theta}=2$ and $p=0.5$.

most meaningful. We provide simulation results in Figures 1 and 2 below.

The model has essentially three parameters that determine the incentive for the interest group to lobby: the probability of finding positive evidence, $q$, the ex ante probability of high marginal utility in any district, $p$, and the relative variation in the tastes across districts, $\bar{\theta} / \underline{\theta}$.

Figure 1 shows how the value of $t^{*}$ is affected by the parameters of the model. Our benchmark values are: $\bar{\theta} / \underline{\theta}=2, q=\frac{1}{2}$, and, $p=\frac{1}{2}$. In the first panel we vary $\bar{\theta} / \underline{\theta}$ from 1 to 10 . Using these parameters we solve equations (1) through (6) numerically, which gives us an implied value of $t^{*}$, the maximum number of policy periods in which the two legislative structures provide lobby groups with the same incentives to engage in information gathering.

We observe that when the intensity of preference for the public good varies between districts less than 400 percent, i.e. $\bar{\theta} / \underline{\theta}<4, t^{*}$ is one. Hence, as long as the taste variation across districts is not extreme it is only in the last policy period that the two legislative structures provide the same incentives for lobby groups to engage in information provision. For extreme values of taste variation, we observe no more than 
$t^{*}=2$ in the present example. In the two next panels, we fix the taste variation at 2 and vary $p$ and $q$. Notice that $t^{*}$ is not affected by variation in $q$ at all (for $p=.5$ ), and only for small values of $p$ is $t^{*}$ greater than one (at $q=.5$ ).

From the example presented in Figure 1 and other, non reported, simulations, it appears that $t^{*}$ is small, and equal to one for a large range of plausible parameters. ${ }^{10}$ Thus, the lack of action in Figure 1 supports the main insight of our analysis: in comparing multiple rounds of legislative bargaining in the parliamentary system with multiple rounds of bargaining in the congressional system, the parliamentary system provides a strictly lower incentives to engage in informational lobbying in most policy periods.

For a small enough degree of taste variations between districts the result can be stated in a stronger form. A sufficient condition for the interest group not to lobby at all, except for in the last policy period is the following:

$$
v_{\text {gov }}^{1}>\psi_{\text {as }}(\bar{\theta}, \bar{\theta})-\psi_{\text {as }}(\bar{\theta}, \underline{\theta})
$$

The right hand side of the inequality denotes the highest gain a proposer can ever achieve from breaking the governing coalition. The expression then says that in the penultimate period the value for the coalition partner of maintaining the government coalition exceeds the gain the agenda setter may obtain by responding to informative messages from the lobby group. If (7) holds, then the lobby can never affect the policy majority in any period except for the last and therefore has no incentive to engage in information provision.

The shaded area in Figure 2 shows the range of parameters for which Equation 7 is

\footnotetext{
${ }^{10}$ Our simulations shows that only very small values of $p$ combined with extreme values of $\bar{\theta} / \underline{\theta}$ induce a "high" $t^{*}$, i.e., $t^{*}$ higher than 5 .
} 

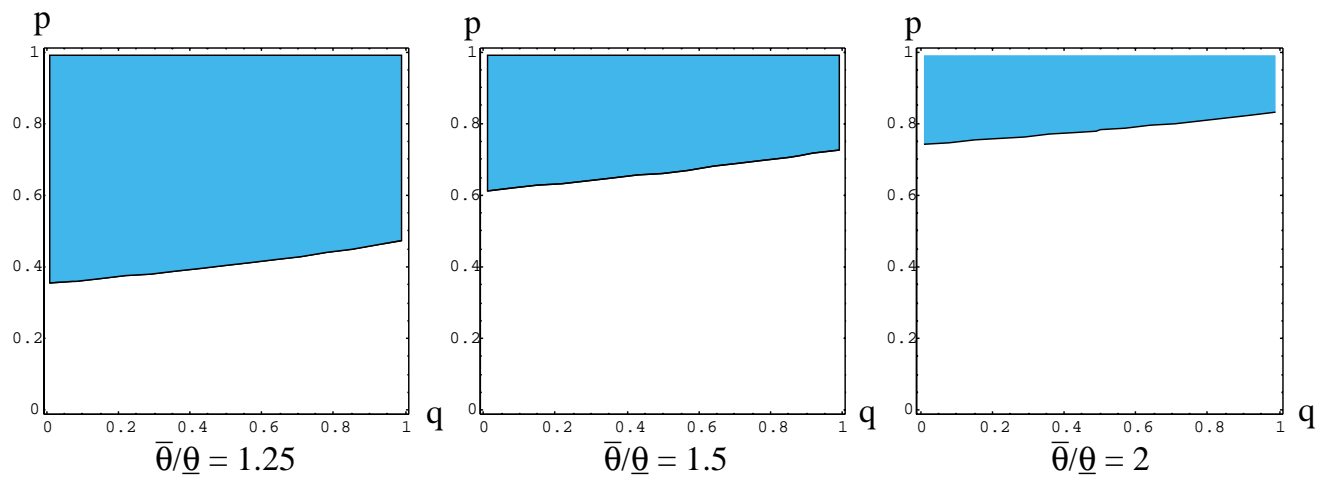

Figure 2: The set of parameters for which a lobby confronting a parliamentary legislature chooses to abstain from information gathering.

satisfied for three different degrees of taste differences. For parameters in this range no lobby will engage in information provision in any policy period, except the final period before an election. The figure confirms the importance of the different incentive provided by the two different legislative structures: When district specific taste difference are relatively small, it is likely that lobby groups confronting a parliament will abstain completely from engaging in informational lobbying.

\section{Robustness.}

In our dynamic framework of informational legislative lobbying we imposed a number of simplifying assumptions. In this subsection we briefly discuss the impact of relaxing three of these assumptions on our comparative institutional analysis.

Our first discussion concerns our simplifying assumption that information search is observable by all players in our model. This clearly simplifies the analysis and highlight the working of the information externality, but it is not crucial for our result. In practice, legislators cannot be expected to monitor interest group activities all too closely. However, if we maintain that players are rational and make the best (equilibrium) pre- 
dictions about other players' unobserved behavior and that players' actions are optimal given their beliefs, then the main insight, that the parliamentary legislature provides less incentive to engage in informational lobbying, survives introducing unobservable information search. The main difference is that in the case of unobservable search, the activity itself does not induce the proposer to revise her beliefs, so that the activity itself does not impose a Bayesian cost. Instead, the proposer infers whether or not the group has an incentive to search and forms her expectations accordingly. Thus, in equilibrium the failure to report a positive finding still carries the Bayesian updating cost.

In our model we assumed for analytical simplicity that the legislature only contained three legislators. Extending the model to any - odd - number of legislators does not affect our main result. In the congressional setting, the value of engaging in information search increases because there it is easier to have an impact on the composition of the policy majority. On the other hand, when the value of government membership is sufficiently high, it is not possible to affect policy composition in the parliamentary system. Hence, the lobby has smaller incentives to lobby in latter system.

Finally, we assumed that the lobbies only care about the aggregate - national - level of the public good. An interest group's benefit is often localized, and it may have a particular knowledge of the local incidence of the public good that it might want to convey to the legislators. In this case, they compete for inclusion of their district in the majority by providing information. Our general result prevails and may even be amplified, since this inclusion motive is absent in the parliamentary system. 


\section{References}

Austen-Smith, David. "Allocating Access for Information and Contributions." Journal of Law, Economics, and Organization, 1998. 14(2): p. 277-303.

Baron, David P., and John A. Ferejohn. "Bargaining in Legislatures." American Political Science Review, 1989. 83: p. 1181-1206.

Baron, David P. "Electoral Competition with Informed and Uninformed Voters." American Political Science Review, 1994. 88(1): p. 33-47.

Baron, David P. "Competitive Lobbying in a Majority-Rule Institution." Mimeo, Stanford University, Nov. 2000.

Bennedsen, Morten and Sven E. Feldmann. "Lobbying Legislatures," forthcoming, Journal of Political Economy, August 2002.

Bennedsen, Morten, and Sven E. Feldmann. "Informational Lobbying and Political Contributions." Mimeo. University of Chicago, 2001.

Calvert, Randall L. "The Value of Information: A Rational Choice Model of Political Advice." Journal of Politics 47, 1985, pp. 530-55.

Cox, Gary W., and Mathew D. McCubbins. Legislative Leviathan: Party Government in the House. Berkeley: University of California Press, 1993.

de Figueiredo, Rui J.P., Pablo T. Spiller, and Santiago Urbiztondo. "An Informational Perspective on Administrative Procedures." Journal of Law, Economics, and Organization, 1999. 15(1): p. 283-305.

Diermeier, Daniel, and Timothy J. Feddersen. "Cohesion in Legislatures and the Vote of Confidence Procedure." American Political Science Review 92(3), 1998, pp. 611-21.

Groseclose, Tim and James M. Snyder "Buying Supermajorities." American Political Science Review, 1996. 90(2): p. 303-16.

John D. Huber. Rationalizing Parliament: Legislative Institutions and Party Politics in France. Cambridge; New York: Cambridge University Press, 1996.

Liebert, Ulrike. "Parliamentary Lobby Regimes." In Parliaments and Majority Rule in Western Europe, H. Döring, Ed. Frankfurt a.M.: Campus Verlag, 1995. p. 407-47.

Lijphart, Arend. Parliamentary versus Presidential Government. New York: Oxford University Press, 1992. 
Loewenberg, Gerhard, and Samuel C. Patterson. Comparing Legislatures Lanham, MD: University Press of America, 1988.

Mayhew, David R. Congress: The Electoral Connection. New Haven: Yale University Press, 1974.

Mezey, Michael L. Comparative Legislatures. Durham, N.C.: Duke University Press, 1979.

von Beyme, Klaus . The Legislator: German Parliament as a Centre of Political Decision-Making Aldershot: Ashgate, 1998.

von Beyme, Klaus. "Interest Grousp in Parliamentary Decisions in the German Bundestag." Government and Opposition, 1998. 33(1). 